\title{
REVIEW
}

\section{Therapeutic Management of Breast Cancer Related Upper Limb Lymphedema}

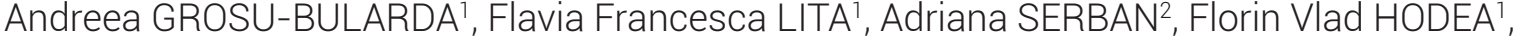 \\ Alexandru STOIAN', Ioan LASCAR ${ }^{1,3}$, Razvan Nicolae TEODOREANU1,3
}

\begin{abstract}
Lymphedema represents a chronic condition with impaired lymphatic transport, having primary and secondary etiologies. The most common type of secondary lymphedema in western countries is represented by breast cancer related upper limb lymphedema.

This condition, once installed, determines limb structure changes, progressive functional impairment, specific complications, consequently impacting the quality of patient's life. An accurate diagnosis is mandatory, using both clinical and imagistic methods with clear definition disease extent as per standardized staging systems, in order to further provide an adequate therapeutic strategy.

The main therapeutic goal in patients with lymphedema is represented by limb volume reduction with subsequent symptoms relief, improving quality of life and avoiding complications such as recurrent infections. Through this paper, we aim to present a comprehensive overview of current therapeutic options of breast cancer upper limb related lymphedema.

Therapeutic approach comprises of non-surgical (conservative) therapy, which is mandatory as initial therapy and surgical procedures for selected cases. Most patients with lymphedema benefit from conservative treatment alone. In non-responsive cases, in patients with progressive disease, in late stage complicated lymphedema, and also recently added as prophylactic strategy, surgical treatment, trough recent developed techniques, offer very good results in long-term control of disease.

Surgical options are classified firstly in physiologic procedures that aim to create new lymphatic channels, promote physiologic drainage of the lymph and should be considered early in the course of the disease, and secondly ablative procedures that reduce through liposuction or various excision techniques the volume of the affected limb. Both types of techniques can be combined to ensure the best functional outcome of the patient.
\end{abstract}

Keywords: breast cancer related lymphedema (BCRL), staging, conservative treatment, physiologic procedures, ablative procedures.

${ }^{1}$ Clinic of Plastic Surgery, Emergency Clinical Hospital, Bucharest Romania

${ }^{2}$ Department of Rehabilitation, Emergency Clinical Hospital, Bucharest, Romania

${ }^{3}$ "Carol Davila" University of Medicine and Pharmacy Bucharest, Romania
Corresponding author.

Flavia Francesca LITA, Clinic of Plastic Surgery, Emergency Clinical Hospital, Bucharest, Romania.

E-mail: flavia16francesca@yahoo.com 


\section{INTRODUCTION}

Lymphedema is a progressive and debilitating condition affecting 250 million people worldwide characterized by impaired lymphatic transport due to structurally and functionally altered lymphatic vessels caused by obstruction, malformation or hypoplasia, resulting in functional deficit, decreased quality of life and high infection rate ${ }^{1-5}$.

Lymphedema can be further divided into either primary or secondary lymphedema. Upper extremity primary lymphedema is a rare entity and is caused by congenital lymphatic dysfunction ${ }^{6}$. In contrast, secondary lymphedema is induced by extrinsic disruption of a normally developed lymphatic system, trough trauma, infections, surgery or radiotherapy determining anatomical segment enlargement, deposit of fibroadipose tissue and lymphatic fluid accumulation in the interstitial space ${ }^{1}$.

In the United States secondary lymphedema due to malignancy or its treatment is recognized as the most common origin of secondary upper limb lymphedema. These malignant conditions consist of breast cancer, melanoma or lymphoma ${ }^{7-10}$.

In developed countries, breast cancer-related lymphedema(BCRL) is the most common type of secondary lymphedema. Breast cancer related lymphedema occurs in approximately 1 in 5 patients treated for breast cancer ${ }^{11}$.Due to improved survival strategies (89.7\% survival rate at 5 years) it is estimated that by 2026 the number of breast cancer survivors will reach 4.571.210 becoming a financial health system burden with considerable higher costs for patients who associate BCRL ( $\$ 58.088$ per patient) versus non-BCRL patients $(\$ 31.819){ }^{12}$.The incidence of lymphedema increases from $20 \%$ at one year after breast cancer treatment to $40 \%$ after ten years, the cumulative average risk being $28 \%{ }^{9,13}$.

Risk factors for BCRL can be divided in treatment related and non-treatment associated. The most frequent treatment related risk factors for BCRL include axillary node dissection (ALND) and regional lymph node radiation (RLNR), mastectomy, lack of breast reconstruction and chemotherapy. Axillary surgery, both ALND and SLNB( sentinel lymph node biopsy) put the patient at increased risk of developing lymphede$\mathrm{ma}$, the incidence being four time higher for ALND ${ }^{11}$, ${ }^{14}$. SLNB is a less invasive procedure with reduced morbidity that can offer similar survival rates with an identified upper limb lymphedema risk of $7 \%$ according to the American College of Surgeons Oncology Group ${ }^{15}$.

$\mathrm{BCRL}$ is greatly diminished in patients who receive lumpectomy versus the patients treated with mastectomy or modified radical mastectomy.Furthermore, mastectomy alone has been reported to be a risk factor for lymphedema development ${ }^{15}$. Miller et al, based on a prospective cohort study including 891 mastectomies, reported that immediate breast reconstruction can substantially decrease the lymphedema risk with implant-based reconstruction offering a more significant reduction in risk compared to immediate autologous reconstruction ${ }^{16}$. Patients benefiting from immediate breast reconstruction usually have skin-sparing mastectomies, with preservation of the skin envelope including subcutaneous lymphatic channels under the skin, while in patients in which immediate reconstruction is not indicated, an extensive resection of breast and axillary skin is performed also developing cicatricial tissue adherence and fibrosis with possible impairment of lymphatic flow $^{16}$. Autologus breast reconstruction can lower the risk of later onset BCRL by promoting angiogenesis and decreasing local scarring. Also, expander-implant breast reconstruction is confirmed to endorse the expression of vascular endothelial growth factor (VEGF), a major lymph angiogenesis promoter by inducing tissue ischemia ${ }^{15-16}$.

Radiation therapy is regarded as an independent risk factor for BCRL even in the absence of axillary surgery ${ }^{9}$. Concerning chemotherapy, current data is still conflicting, a taxane based adjuvant regimen (using Docetaxel) being found to increase the cumulative incidence of BCRL ${ }^{17}$.

Additional non-treatment associated risk factors include genetic predisposition, BMI $>30 \mathrm{~kg} / \mathrm{m} 2$ and cellulitis. Greater BMI is considered an independent risk factor for BCRL, obese patients being 3.6 more likely to develop lymphedema. Cellulitis is a notable risk factor with a feedback loop in which cellulitis increases BCRL risk and BCLR raises the risk of further infection $^{14,18,19}$.

A series of preventive measures are recommended for breast cancer patients with high risk of developing lymphedema, the most important being maintenance of a normal body weight and enrolling in a supervised sustained exercise program ${ }^{20}$. 


\section{BREAST CANCER-RELATED LYMPHEDEMA EVALUATION}

\section{Lymphedema assessment}

The diagnostic of upper limb lymphedema is based on patient's medical history, clinical examination and physiologic measurement. The common clinical symptoms associate swelling, pain, heaviness, numbness and impaired limb function. Frequently seen clinical signs include skin changes (hyperkeratosis, papillomatosis, dermal lichenification, lymphedema rubra, lymphorrhea, elephantiasis verrucosa nostra, folliculitis, lymphangitis, cellulitis, lichen simplex cronicum etc.) pitting and non-pitting edema ${ }^{21-23}$.

The most commonly used method to quantify lymphedema is sequential limb volumetric measurement. Circumferential measurement uses 4 anatomical landmarks for the upper limb: metacarpal-phalangeal joints, the wrist, $10 \mathrm{~cm}$ distal to the lateral epicondyles, and $15 \mathrm{~cm}$ proximal to the lateral epicondyles (Figure $1)^{9,24}$. Other option is practicing measurements at specified interval( for example $4 \mathrm{~cm}$ ) starting from a fixed point $^{25}$. Lymphedema is arbitrarily explained as a $2-\mathrm{cm}$ difference in limb circumference, a $200-\mathrm{mm}$ increase in limb volume or a 5\% to $10 \%$ discrepancy in limb volume compared with the unaltered limb ${ }^{9,12}$.

Water displacement plethysmography represents a valuable technique for limb volume evaluation, mea-

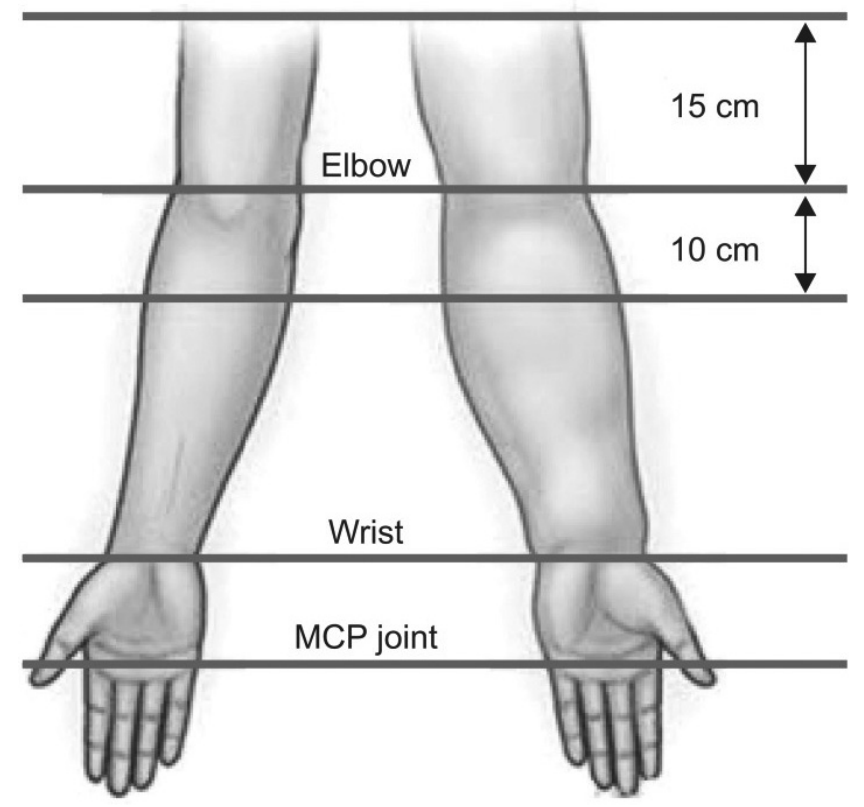

Figure 1. Circumferential limb measurement in lymphedema patients Adapted after Yoo JN et al.[24], under the terms of the Creative Commons Attribution Non-Commercial License (http://creativecommons.org/licenses/by-nc/4.0) suring the volume of water dislocated by the lymphedematous limb when being placed in a large cylinder of water ${ }^{25}$.

Perometry can assess limb volume and compare it with the unaffected side by using an optical electronic scanner ${ }^{25}$.

Tonometry can quantify tissue fibrosis by measuring the force needed to make an indentation on the skin. Fibrotic changes evaluation is useful for monitoring treatment efficiency and dictate further management of the case ${ }^{25,26}$.

Bioimpedance spectroscopy (BIS) is a modern diagnostic method that consists in detecting the physical reaction to application of weak alternating electrical current with the purpose of measuring the volume of extracellular fluid. It was proven that BIS can identify subclinical stages of lymphedema in breast cancer patients . Although it is a real-time, objective monitoring technique it has a high false-negative rate $^{26-28}$.

Color duplex ultrasound is a non-invasive, inexpensive and an easy to reproduce method that can provide information about the etiology of edema. The CDU (Color duplex ultrasound) can reveal fluid in the plane above and below fascia, modifications in the structure of lymph nodes, nodules and cysts within the lymphatic system or ectatic lymphatic vasculature. It appears that CDU corresponds with theThe International Society of Lymphology(ISL) staging system of lymphedema ${ }^{29}$.

Computed tomography is used to assess the alterations in the skin, subcutaneous tissue and muscles in lymphedema patients. The distinctive lymphedema sign consists in a honeycomb pattern. It can also give information about the etiology of edema such as a direct blockage of the lymphatics (e.g. cancer), fluid collections or skin thickening. CT can provide a $3 \mathrm{D}$ aspect of the lymphedematous limb. As disadvantages we can include its lack of sensitivity and the incapacity of real-time monitoring ${ }^{29,30}$.

Magnetic resonance imaging in comparison with computer tomography, can provide accurate anatomic and functional information on both the lymphatic vessels and nodes but with higher cost and laborious technique. Magnetic Resonance Lymphangiography (MRL) is a noninvasive technique that can visualize individual lymphatic vessels and dermal backflow. The main difference between MRL and other contrast enhanced MR imaging is the route of contrast administration (for MRL a gadolinium-based contrast agent is injected intracutaneously).Dynamic contrast enhanced MRL can potentially provide a noninvasive grading of 
lymphatic disfunction (by estimating lymphatic flow velocities), facilitate the selection of patients suitable for microsurgery and evaluate postoperative results ${ }^{31,32}$.

Lymphoscintigraphy (LSG) represents the "gold standard" imaging method and can detect lymphedema in its early stages. By injecting a radiotracer intradermally into the interdigital space it can emphasize the lymphatic functional status of the upper limb. The qualitative analysis of LSG can evaluate the following: presence or absence of axillary/elbow lymph node uptake, presence of linear, dilated or absent lymphatic ducts, presence and location of dermal backflow; the quantitative assessment of LSG involves the evaluation of radionuclide transit times. The disadvantages of LSG include lack of standardization, radionuclides employed, dose, injection site and substance dispersion method. It can only assess deep lymphatic flow and not the subdermal lymphatics ${ }^{13,29,33}$.

Indocyanine Green (ICG) Lymphography is the most commonly used procedure that can offer precise visualization of the superficial lymphatic channels. The imaging technique involves the intradermal injection of fluorescent dye (ICG) and image acquisition using a near-infrared camera and a laser light source. The ICG lymphatic patterns differ from normal linear to abnormal backflow in obstructive lymphedema. In more advanced stages the lymphatic patterns progress to splash, stardust and finally to the diffuse pattern. The procedure has several advantages including no exposure to radiation and detailed real time assessment of the superficial lymphatic system. This procedure drawback is represented by the inability to assess the deep lymphatics (at more than $1 \mathrm{~cm}$ depth) ${ }^{34-36}$.

Near-infrared fluorescence (NIRF) imaging with intradermal injection of ICG can gather a sequence of images within milliseconds enabling the evaluation of the lymphangion activity. NIRF can show a reduced lymph propagation velocity and contractile rate of the lymphangions in lymphedematous limbs. Proposed diagnostic criteria for upper limb are $0.3 \pm 0.3$ propulsions/min(normal values being $1.3 \pm 1.2$ propulsions/ $\mathrm{min}$ in the arms). It was proposed as a method to guide the conservative approach through its ability to identify the compensatory drainage pathways ${ }^{29,37,38}$.

All the methods presented above in the evaluation of lymphedema are used to accurately diagnose the severity of disease, establish a correct differential diagnosis from other pathologies associated with upper limb edema and offer dynamic monitoring of the response to the applied therapeutic strategy. If left untreated,
BCRL progress to irreversible upper limb edema, fibrosis, persistent symptoms as pain and paresthesia, marked functional impairment, ulceration, decrease in immune responsivity, posing high infectious risk(recurrent cellulitis and erysipelas) and a rare but very severe complication represented by the occurrence of lymphangiosarcoma (Stewart-Treves syndrome) ${ }^{37,39-41}$. Figure 2 illustrates an infectious complication in upper limb postmastectomy lymphedema and figure 3 a late stage, complicated BCRL case.

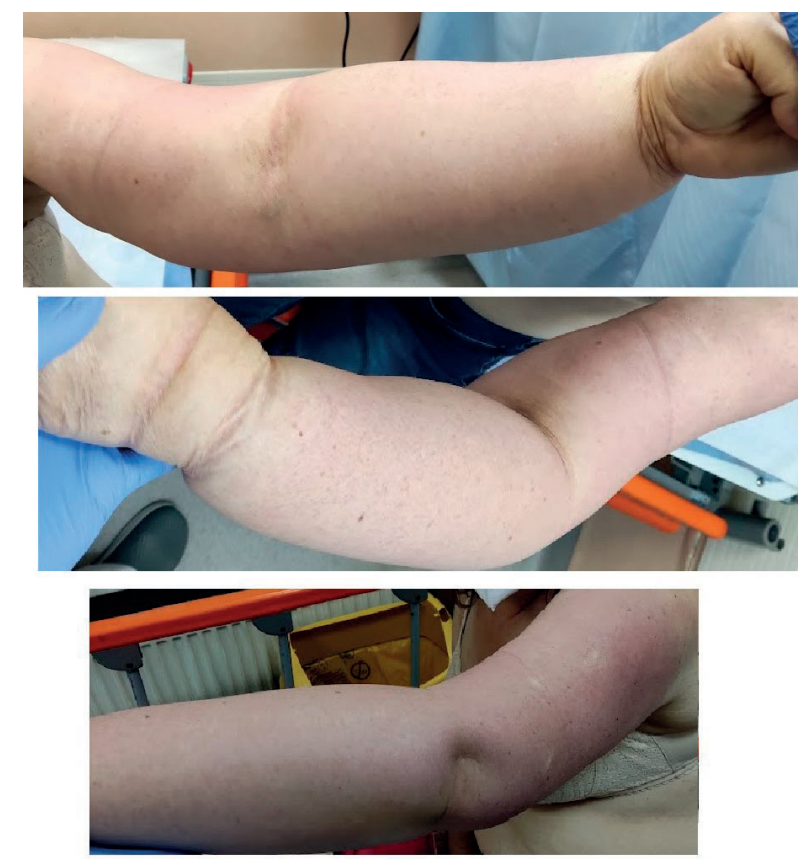

Figure 2. Infectious complications (erysipelas) in a 65-year-old female patient with breast cancer related lymphedema
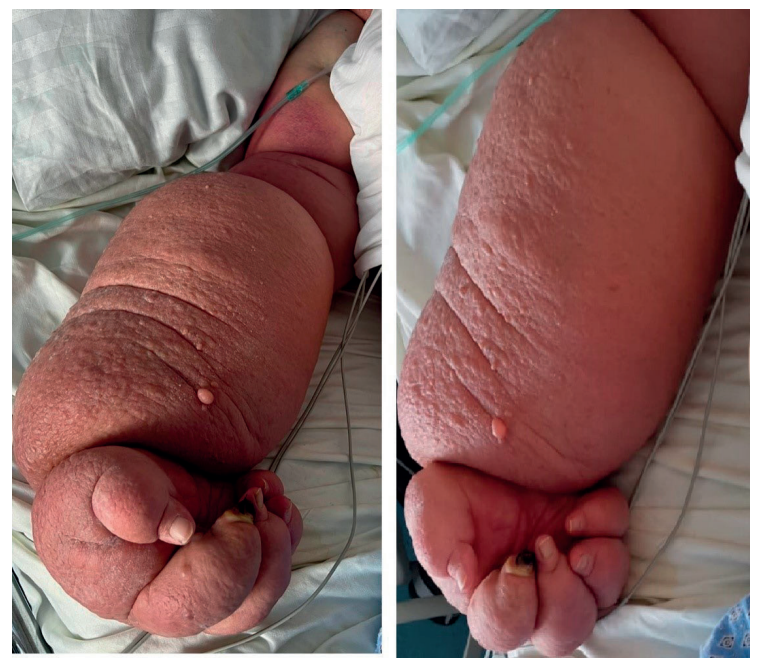

Figure 3. Severe neglected lymphedema, elephantiasis, in a 81-year-old female patient, with non-functional and subsequent structural and infectious complications 


\section{Lymphedema staging}

Currently, there is no ideal staging system for lymphedema evaluation, existing various international classification methods. The staging systems are mandatory to uniformize a scientific communication in the lymphedema field and for the guidance of therapeutic strategy in a standardized manner ${ }^{42}$.

The most widely used lymphedema staging tool is the The International Society of Lymphology(ISL) grading system which evaluates the disease severity (being based on clinical assessment) and classifies lymphedema into four stages. The main disadvantage of this classification is the lack of objective measurements or imaging evaluation ${ }^{43}$.

The staging criteria are decided by history, diagnostic tools, clinical evaluation, pitting test, Stemmer sign, and skin changes. Edema reduction with limb elevation and the pitting test are used to discern between stages I and II whereas stage III is characterized by the presence of any skin changes.Advantages of this clinical staging system consist of high accessibility, low cost, being also rapidly performed ${ }^{23,43,44}$.

With the development of imaging tools new classification systems have emerged. Campisi et al proposed a staging system which integrates clinical presentation with lymphoscintigraphic patterns ${ }^{45}$.

MD Anderson staging system (Chang et al) is based on Indocyanine green (ICG) lymphangiography features and aims to assist surgical planning in arm lymphedema. Moreover, the authors propose this classification as a selection tool for lympho-venular bypass $^{46,47}$.

The lymphangiography using Indocyanine green staging is superior to clinical staging for breast cancer lymphedema patients and can guide personalized microsurgical treatments. Disadvantages of ICG lymphangiography are high cost, time consuming and a low risk of allergic reactions ${ }^{48}$.

Table 1 illustrates the most used classification systems mentioned above ${ }^{9,43,45,46,47}$.

\section{THERAPEUTIC OPTIONS}

The main therapeutic goal in patients with lymphedema is represented by limb volume reduction with subsequent symptoms relief, improving quality of life and avoiding complications as recurrent infections. Therapeutic management comprises non-surgical (conser-

Table 1. Lymphedema classification systems

\begin{tabular}{|c|c|c|c|}
\hline & ISL & Campisi & Chang (MD Anderson) \\
\hline 0 & $\begin{array}{l}\text { Latent or subclinical condition where } \\
\text { swelling is not present despite impaired } \\
\text { lymphatic transport. It may exist months } \\
\text { or years before overt edema occurs. }\end{array}$ & & No dermal backflow \\
\hline I & $\begin{array}{l}\text { Early accumulation of fluid relatively } \\
\text { high in protein content (i.e., compared to } \\
\text { venous edema). Edema subsides with limb } \\
\text { elevation. Pitting can be present. }\end{array}$ & $\begin{array}{l}\text { Stage IA: No clinical edema despite the presence } \\
\text { of lymphatic dysfunction as demonstrated on } \\
\text { lymphoscintigraphy. } \\
\text { Stage IB: Mild edema that spontaneously regres- } \\
\text { ses with elevation. }\end{array}$ & $\begin{array}{l}\text { Many patent lymphatic vessels, with minimal, } \\
\text { patchy dermal backflow. }\end{array}$ \\
\hline II & $\begin{array}{l}\text { Early - Pitting is present which does not } \\
\text { resolve with elevation alone. } \\
\text { Late - Tissue fibrosis develops, pitting } \\
\text { may or may not be elicited. }\end{array}$ & $\begin{array}{l}\text { Persistent edema that regresses only partially } \\
\text { with elevation. }\end{array}$ & $\begin{array}{l}\text { Moderate number of patent lymphatic vessels, } \\
\text { with segmental dermal backflow. }\end{array}$ \\
\hline III & $\begin{array}{l}\text { Lymphostatic elephantiasis where pitting } \\
\text { is absent. } \\
\text { Trophic skin changes, lipodystrophy, warty } \\
\text { skin overgrowths develop. }\end{array}$ & $\begin{array}{l}\text { Persistent, progressive edema; recurrent } \\
\text { erysipeloid lymphangitis }\end{array}$ & $\begin{array}{l}\text { Few patent lymphatic vessels, with extensive } \\
\text { dermal backflow involving the entire arm. }\end{array}$ \\
\hline IV & & Fibrotic lymphedema with column limb. & $\begin{array}{l}\text { No patent lymphatic vessels seen, with severe } \\
\text { dermal backflow involving the entire arm and } \\
\text { extending to the dorsum of the hand. }\end{array}$ \\
\hline $\mathrm{V}$ & & $\begin{array}{l}\text { Elephantiasis with severe limb deformation, } \\
\text { including scleroindurative pachydermitis and } \\
\text { widespread lymphostatic warts. }\end{array}$ & ICG does not move proximally to injection site \\
\hline
\end{tabular}


vative) therapy and surgical therapy for selected cases. Most patients with lymphedema benefit from conservative treatment, but also surgical treatment, through recent developed techniques, offer very good results in long-term control of disease ${ }^{8,49}$.

\section{Conservative treatment}

Patient education, monitoring and early refer for lymphedema management are the key therapeutical steps according to $2020 \mathrm{NCCN}$ breast cancer guidelines. A significant number of studies acknowledge the importance of early detection and treatment of BCRL $^{9,50}$.

The initial approach of clinically evident lymphedema should imply conservative (non-operative) therapy. Among conservative treatments, complex decongestive therapy (CDT) (also known as complex decongestive physiotherapy, combined physical therapy, and complex physical therapy) is endorsed by long term experience and is considered the most effective method to reduce upper limb lymphedema volume after breast cancer. Other complementary options to CDT include intermittent pneumatic compression (IPC), taping, extracorporeal shock wave therapy, photobiomodulation or vacuum suction therapy ${ }^{51-53}$.

Complete decongestive therapy is recognized as the standard management of lymphedema, with demonstrated efficacy, being a multimodal approach that combines manual lymphatic drainage, daily compressive bandaging, exercise and proper skin care routine. CDT involves 2 phases, the first being intensive phase and the latter being maintenance phase $\mathrm{e}^{51,52,54}$.

The first phase (typically 4 weeks) aims to diminish limb volume by mobilizing the protein rich congesting fluid and initiation of conjunctive tissue formation downregulation. The maintenance phase aims to keep the long-term results obtained in the first phase by utilizing low resistance short-stretch layered bandages. The purpose is to enter the lymphedema latency stage (no notable edema despite limited lymphatic system function). Dynamic compression therapy should aim to achieve normal lymphatic drainage and therapeutic compression ranges ${ }^{51-55}$.

The objectives of such therapy should target lymphatic function improvement, smoothening of fibrosclerotic irregular areas, diminishing collagen deposits, while limiting microbial growth and local infection onset. The physiological effects of compression are interstitial fluid migration, lowering the venous pressure, lowering lymphatic inflow, stimulation of lymph formation, enhanced lymphatic return flux ${ }^{53,55}$.

Among the contraindications of CDT we can include the following: acute erysipelas, acute thrombophlebitis, phlebothrombosis, documented allergy to compression material, severe cardiac failure or peripheral occlusive arterial disease ${ }^{56}$.

Manual Lymphatic Drainage (MLD) is a massage technique in which rhythmic pressure stimuli are applied to subcutaneous tissues, therefore manipulating only the filaments anchored to capillaries and smooth muscles. Mild pressure diminishes sympathetic tonus and promotes the parasympathetic response. Stimulation of healthy lymph nodes is enhanced, raising the trophic properties of lymphatic channels, elevating the suction effect. In BCRL cervical ganglia can be stimulated in order to promote lymphatic return to the venous system ${ }^{53,57}$.

MLD can also provide analgesic properties, ensuring accelerated drainage of nociceptive factors from tissues, through "gate control" effect, consequently improving anxiety, sleep and quality of life. Although the effectiveness of manual lymphatic drainage is not yet clearly emphasized, it can offer supplementary benefits in combination with other compression therapies. Local contraindications for upper arm manual lymphatic drainage application include carotid sinus syndrome or hyperthyroidism ${ }^{53,57,58}$.

Compression therapy is the most important component of CDT and can be performed using multi layered compressive bandages. Laplace law explains the importance of gradual compression, by using elastic materials. A normal extremity can be compressed with cylindrical gradual pressure, utilizing the tension between the distal and proximal end of the extremity ${ }^{52,59}$.

The pressure at the distal segment with the lowest diameter, is bigger than the one on the root limb. At rest, the pressure that the bandage exhibits on the tissues (no sudden contractions) presents a value that depends on the exhibited tension during the time of applying it, therefore, a bandage with a higher extensibility property means larger pressure upon tissues at rest. The shortstretch bandages used for lymphedema management exert reduced pressure gradients during rest hence the tourniquet effect on the limb is decreased. Work pressure is provided when the muscle contracts (higher for low-stretch bandage). The favorable effects of compression garments include the reduction of net filtration, promotion of fluid resorption, increase muscular pump 
efficiency during active times and decrease interstitial fibrosis, improving functionality and quality of life $\mathrm{f}^{51-53}$.

In lymphedema maintenance treatment phase, wearing compressive stocking is indicated. Some degrees of compression are established depending on pressure that exhibits on the skin surface (gradient is necessary to be exhibited from distal to proximal). Different styles can be employed, either personalized or standard. Preferably they are personalized, especially for deformed limbs. Daily washing helps them maintain their elastic properties. Compression under $20 \mathrm{mmHg}$ is not usually used in lymphedema. Compression over $20 \mathrm{mmHg}$ is useful for postural mild edema or mild venous edema, providing an antiembolism effect. The stockings must be changed every 6 months, if worn daily ${ }^{51,53,60,61}$.

Kinesio-Taping represents another tool in improving lymphatic drainage, trough lift of the skin from the underlying fascia with reduction of the interstitial pressure and stimulation of the blood and lymph flow. Taping may be an alternative to compressive therapy for patients with contraindications. Taping is being considered a safe procedure, but care must be taken to not cause consecutive skin tearing. Narrow strips of kinesio tapes are applied along the lymphatic system pathway in the upper limb, shoulder and trunk $\mathrm{k}^{51,53}$ (Figure 4).
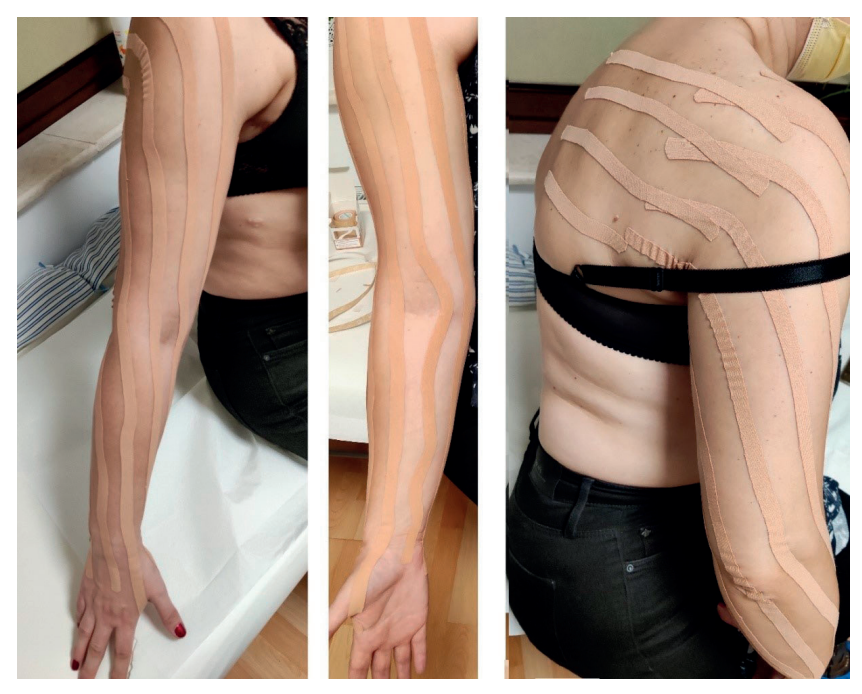

Figure 4. Kinesio tapes applied for upper limb postmastectomy lymphedema

It was demonstrated that kinesio taping has an important role in both lymphedema prevention after mastectomy and axillary clearance through decreasing the lymphatic overload and in long-term management of the installed lymphedema ${ }^{53}$.

Exercise. Various types of exercises have been presumed suitable in patients with lymphedema, including water exercises, stretching, Pilates,yoga, Thai-chi, swimming, recreational sports, resistance exercises, weight training, and aerobic exercises. Isometric, repetitive exercises should be attempted, with gradual progression. As a rule, the exercises must be performed with worn compressive bandages and intensity and duration should be gradually increased. The movements that cause discomfort or pain must be avoided. The extremity should be dynamically monitored for volume change. Posture exercises can be important in patients with breast cancer (kyphotic posture with decreased movement in the shoulder and cervico-brachial pain) ${ }^{51,53,62}$.

Lymphedema patients may present chronic skin modification such as thickening, hyperkeratosis, skin folding, fissures, lymphorrhea. These complications determine a higher infectious risk, with worsening of lymphedema and depreciate the quality of life. Therefore, patients should be advised to perform daily rigorous hygiene measures, keep adequate moisture with daily emollient applications and to avoid skin impairment or trauma ${ }^{51,63,64}$.

\section{Complementary conservative treatments}

Intermittent pneumatic compression (IPC) mimics the effect of muscular pump (30-60 mmHg). Multi chambered devices are preferred and are inflated sequentially from distal to proximal to deliver external compression. The therapy reduces episodes of cellulitis and ulcerations, as well as leading to formation of tissular channels and communication channels for lymphatic drainage. It is considered benefic for patients with reduced mobility and accepted home based modality of treatment ${ }^{51}$.

Vacuum suction therapy is a massage technique performed with a mechanical device that creates a suction force which mobilizes the skin folds. With demonstrated effects on burn scars and lipodystrophy, it can reduce mechanical tension associated with scar retraction, diminishing fibrotic induration, tightness, and functional impairment ${ }^{51,65}$.

Extracorporeal shock wave therapy (ESWT) uses mechanical energy to produce a cavitation effect leading to microlesions in the inflamed tissue which release anti-inflammatory compounds with additionally improved microcirculation. In rat models it was confirmed 
enhanced expression of vascular endothelial growth factor-C and of its receptor, VEGF receptor 3, and increased formation of lymphatic vessels ${ }^{51,66}$.

\section{Electrostimulation}

Electric stimulation in lymphedema patients has a benefic role, reducing limb volume, through improving of lymphatic flow and also stimulating skeletal musculature ${ }^{53}$.

\section{Pharmacologic Treatment of Lymphedema}

Due to high prevalence of lymphedema and lack of curative measures many targeted therapies have been proposed by clinical and experimental studies. The rationale used by these studies addresses the pathogenic mechanisms of lymphedema particularly tissue inflammation, fibrosis and lymphangiogenesis ${ }^{67,68}$.

Ketoprofen is shown to reduce edema, normalize histologic changes, ameliorate dilated lymphatics, and improve epidermal thickness on mouse models ${ }^{69}$. It was postulated that the paradoxically increase in tumor necrosis factor (TNF)- $\alpha$ levels consequently induced VEGF C expression and lymphangiogenesis ${ }^{70}$.

Benzopyrones have been successfully used in venous disease treatment for their antiedematous properties. Coumarins or alpha-benzopyrones can reduce high-protein rich edema and flavonoids or gamma-benzopyrones decrease vascular leakage and inhibit the enzymatic promoters of inflammation, representing promising pharmacological strategies for lymphedema patients ${ }^{68}$.

Topical Tacrolimus by CD4+ T cells depletion significantly reduces lymphedema, inflammation, fibrosis, adipose tissue deposition and enhances lymphatic function on mouse tail model, without the risk of systemic immunosuppression ${ }^{71}$.

Adipose-derived stem cell (ADSCs) has emerged as a novel therapeutic approach due to their multipotent progenitor cells properties and capacity of enhancing lymphangiogenesis by promoting VEGFR-3 expression. Both animal and human studies show promising outcomes in decreasing limb volume after the injection of ADSCs with low immunogenic effects ${ }^{72}$.

\section{SURGICAL TREATMENT}

Effective lymphedema surgical procedures continue to develop due to the constant advancement in this field which includes a better insight of the lymphatic system anatomy and lymphangiogenesis, better imaging technology and renewed interest in the microsurgical techniques. These surgical procedures can produce long lasting volume reduction, but the success of lymphedema operation is largely dependent on training, expertise and individualized therapy integrated into the treatment plan before and after surgery ${ }^{73,74}$.

These operative strategies are classified in either ablative or physiologic procedures. Physiologic procedures (vascularized lymph node transplant or lymphovenous anastomosis) create new lymphatic channels, promote physiologic drainage of the fluid trapped within the lymphedematous limb and should be considered early in the course of the disease, before the onset of substantial tissue fibrosis, fat deposition and lymphatic destruction. In contrast, reductive techniques (ablative procedures) that remove fibrofatty tissue can be performed at any time during the extent of the disease and are typically used as 'rescue' procedures in advanced stages of lymphedema where physiologic therapies may not provide adequate volume reduction or after physiologic procedures to address the fat and fibrosis component of the lymphedematous limb. Regularly used ablative procedures consist of subcutaneous excisional procedures and liposuction $1,8,46,47,73-76$.

Standard lymphedema surgical indications include: no response to medical treatment after 6 months; recurrent episodes of cellulitis or lymphangitis; untreatable pain; lymphangiosarcoma; availability of a specialized lymphatic surgery center; after ganglion excision for malignancies with increased risk of lymphedema development; cosmetic reasons in selected patients ${ }^{73,76}$.

\section{Physiologic procedures}

LVA (lympho-venous anastomosis) is used for refractory lymphedema to non-operative methods, if the volume reduction after CDP is under $50 \%$, recurrent episodes of lymphangitis, pain or unsatisfactory results for the patient. It is contraindicated in acute episodes of dermato-lymphangitis, lymphatic hypoplasia and in patients with venous diseases such as deep venous thrombosis and varicose veins ${ }^{73,76-79}$.

The procedure involves the microsurgical anastomosis between superficial lymphatic vessels and neighboring venules permitting the lymphatic fluid to bypass obstructed lymphatics. With the latter advancement of the supermicrosurgical techniques (anastomosis of the vessels between $0.2-0.8 \mathrm{~mm}$ ) based on the concepts of professor Isao Koshima, the recent methods of lymphaticovenular anastomosis surpass the efficacy of previous performed LVA ${ }^{80}$. 
Lymphatic vessel to vein or lymphatic node to vein anastomosis can be performed. The anastomosis of nodule to vein was practically abandoned due to the increased thrombogenic effect of the lymphatic node pulp. In the upper limb, LVA is performed on the ventral and medial side of the forearm, using both superficial and deep collecting systems. Preoperative use of indocyanine green (ICG) lymphangiography is carried out to determine the location of the aimed lymphatic vessels. ICG is absorbed by the lymphatic pathways when injected into the subcutaneous tissue rather than intravascularly. Using various infrared cameras, the lymphatic system can be mapped with identification of functional lymphatic channels and precise placing of the incisions with high success rates ${ }^{79-82}$. Under local anesthesia, incisions of $2-3 \mathrm{~cm}$ are performed at the chosen bypass area. A surgical microscope is employed using a 20-30 times magnification. Subdermal venous vessels with a diameter of $0.6-1.0 \mathrm{~mm}$ are anastomosed with lymphatics to create Koshima supermicro- LVA shunts. Nylon sutures 11.0 (for vessels of around 0.30$0.80 \mathrm{~mm}$ in diameter $)$ or $12.0(0.20-0.45 \mathrm{~mm}$ in diameter) are preferred. The most common anastomotic configuration is end-to-end while end-to-side configuration is preferred when the venular caliber is twice the lymphatic vessel caliber ${ }^{80,81,83,84}$. Small caliber veins of $0.5 \mathrm{~mm}$ are chosen because larger veins have bigger venous pressure, increasing the risk of backflow. As many lymphaticovenular anastomosis as possible are created to promote shunting of lymphatic fluid into the venous system. Lymphatic scintigraphy is useful to verify long term patency anastomosis and describes newly appeared lymphatic pathways, decreased „dermal backflow", disappearance of the contrast material (at the level of LVA) and its passing through the blood ${ }^{70,81,85,86}$.

Chang et al. determined a decrease of $61 \%$ in upper extremity volume for patients with stage 1 or 2 lymphedema (according to the MD Anderson lymphedema staging), in contrast to a $17 \%$ mean volume reduction in patients with stage 3 or 4 lymphedema, noticing that LVA is more efficient in the early lymphedema stages compared with patients with advanced disease ${ }^{46}$.

The Center of Lymphatic Surgery and Microsurgery in Genoa, Italy, has achieved long lasting clinical outcomes for more than 40 years by utilizing MLVA/ MLVLA (Multiple Lymphatic-Venous-Lymphatic Anastomoses) performed in a single surgical site using larger lymphatics attached to collateral branches of the main veins in proximity to vein valves in order to avoid backflow of blood and the closure of the anastomosis. In this way, the valvular pumping suction force transports the lymph directly through the anastomosis to prevent thrombosis ${ }^{87}$.

In patients undergoing treatment for breast cancer a new prophylactic approach has been considered- Lymphatic Preventative Healing Approach (LYMPHA), in which the lymphatic vessels draining the arm are connected to a recipient vein in the axilla to maintain the drainage of the arm preventing patients from developing lymphedema. A simplified version of LYMPHA used during the surgery of ALND dramatically decreases the lymphedema rate to $3 \%$ compared with ALND alone, which has a higher rate of $13 \%{ }^{88,89}$. To identify and preserve the lymphatics draining the arm as well as to differentiate upper arm and breast drainage pathways -Axillary Reverse Mapping (ARM) has shown promising results facilitating lymphatic sparing in up to $67.3 \%$ of patients undergoing ALND. During ARM, tracer is injected into the extremity before lymphadenectomy. Employing this technique during ALND allows the visualization and preservation of the lymphatic pathways and lymph nodes draining the arm, thereby reducing lymphatic vascular system disruption. Axillary reverse mapping can be also combined with immediate lymphaticovenular bypass (LVB) to allow the reconstruction of altered afferent lymphatic pathways to minimize BCRL risk ${ }^{90}$.

Lympho-lymphatic grafts, rarely used, were introduced to improve localized obstruction or interruption of the lymphatic system of either primary or secondary origin. In upper extremity lymphedema, the lymphatic grafts are harvested from the unaffected side or from the lower extremity to bypass the axillary region. The procedure involves placing an upper arm incision distally to the axillary region and a second incision $3 \mathrm{~cm}$ above the clavicle, laterally to the sternocleidomastoid muscle. Between the incisions a tunnel is created and a 18 Fr catheter is inserted. The tube is filled with Ringer lactate solution to avoid friction. The lymphatic grafts are pulled through the tube and end-to-end anastomoses can be performed with $10-0$ absorbable sutures with a „tension-free” technique ${ }^{91}$.

VLNT (Vascularized lymph node transplant) represents an innovative technique for treating moderate-to-advanced stage lymphedema. The most common indications include:stages I-II for patients that are not candidates for LVA (dysfunctional lymphatic channels) with repeated episodes of cellulitis, fibrosis which im- 
pedes LVA, total occlusion of lymphatic drainage on lymphatic scintigraphy, stage III (in combination with partial wedge excision) or treatment for brachial plexus neuropathies which may complicate breast cancer treatment. The procedure involves autologous microvascular transplantation of functional lymph nodes into an extremity to improve physiological lymphatic func$\operatorname{tion}^{8,73,75,76,92,93}$. It is regularly performed by transferring combined deep inferior epigastric artery perforator and superficial inguinal lymph node flaps in patients undergoing postmastectomy breast reconstruction. For patients who do not require or are unable to sustain free abdominal breast reconstruction or already suffer from lower extremity lymphedema, multiple other VLNT options are available. The technique choice depends on patient desirable scar location or risk of donor site lymphedema. The selection of orthotopic (axilla) or heterotopic (wrist/ forearm) placement of the transplanted lymph node is dependent on acceptance of scar locations and the localization of the pitting edema. Reverse lymphatic mapping is fundamental when harvesting from within the axillary or inguinal lymph node basins to avoid the extreme consequence of iatrogenic lymphedema ${ }^{75,76,92-94}$.

Although the exact mechanism regulating lymphatic transfer is unclear, 2 main theories have been accepted: the procedure promotes lymphangiogenesis due to abundant growth factors which are found in the peri-nodular fatty tissues, particularly vascular endothelial growth factor C (VEGF-C) and the formation of new lymphatico-venous drainage pathways which produce a pumping effect driven by perfusion gradients between arterial inflow and venous outflow ${ }^{93}$, ${ }^{95}$. Moreover, autologous transplantation of mesenchymal stromal cells derived from adipose tissue can open a potential new area of expertise for lymphedema treatment ${ }^{72}$.

The VLNT donor sites are lateral inguinal regional (in combination with deep inferior epigastric perforator flap-DIEP or superficial inferior epigastric artery-SIEA), lateral thoracic, submental, supraclavicular or greater omentum/gastroepiploic nodes flaps ${ }^{92,93,96}$.

In breast cancer reconstruction DIEP flap can incorporate vascularized abdominal wall lymph nodes and when the DIEP anastomosis is done with the mammary vessels the VLNT must be dissected on the other side of the pedicle. In this situation the vascular supply of the VLNT flap should not be assumed to be carried by the DIEP flap. The decision to perform an additional arterial, venous, or dual microvascular anastomosis is still a matter of debate. Intraoperative ICG angiography can determine the perfusion status of the transferred lymph nodes and if compromised supplementary vascular connections can be employed ${ }^{96}$.

The recent combination of LVA and VLNT described by Chang has a synergistic effect and can provide superior outcomes to either one alone. The association of breast reconstruction, LVB and inguinal to axillary node transfer (BRILLIANT) has led to a new emerging approach which aims to augment the outcomes in patients who have breast cancer-related lymphedema with the assistance of supermicrosurgical techniques ${ }^{74,97}$. Masia et al., introduced the concept called T-BAR (total breast anatomy restoration), approaching in the same operative procedure the breast reconstruction and lymphedema surgical management, using an abdominal free flap containing also the lymph nodes, with double vascularization and in some cases performing lymphatic-lymphatic anastomosis between the vessels of the transplanted lymph nodes and axillary sectioned lymph vessels in recipient area ${ }^{92}$.

Although the described physiologic procedures are successful for disease progression control, it is important to emphasize that they will not improve the degree of fibrosis and adipocyte hypertrophy installed prior to treatment. These approaches are adequate only in the initial stages of lymphedema. In more advanced lymphedema stages excisional procedures may be required to decrease pain and morbidity ${ }^{98}$.

\section{Ablative procedures}

The first reported surgical procedure for lymphedema treatment was a debulking technique introduced by Charles in the early 1900 . However, the hazardous use of these procedures has led to poor outcomes and they were progressively abandoned for many decades due to associated morbidity and questionable long term results. Interest in these techniques has been recently restored after the emerging of some modified versions of the original operation ${ }^{99}$.

Although ablative procedures do not address the stem cause of lymphedema, they aim to reduce the limb volume and its associated morbidity by eliminating the fibrofatty tissue with direct excisional methods or liposuction. The indications should include stage III and IV and inefficient conservatory measures, disease progression to the final stage despite maximal treatment over a period of 2 years by the multi-disciplinary team (medical failure) or raised frequency of systemic sepsis ${ }^{76,93,100}$. 
Lipoaspiration/Suction assisted lipectomy (SAL)

Lipoaspiration or suction assisted lipectomy (SAL) is a minimally invasive procedure for lymphedema treatment. It reduces complication risks associated with open excisional techniques. The use of liposuction was introduced by Brorson and Svensson who investigated the utility of combining lipoaspiration with compression therapy ${ }^{101}$.

Multiple theories have been recognized regarding the fat tissue hypertrophy supporting the idea that the adipose cell is an endocrine organ, a cytokine activated cell and adipogenesis is the result of lymphatic fluid stasis which upregulates the expression of fat differentiation markers ${ }^{102,103}$.

Excess limb volume without existence of pitting edema implies that the adipose tissue deposit is the responsible cause. Liposuction can control the fat overload, not fluid, meaning that it is feasible as an adjuvant technique after lymphatic excess has been controlled. Accumulated lymph must be drained using conservatory methods which are mandatory before the procedure. Should the drainage be rendered unsatisfactory, surplus tissue can undergo lipoaspiration. Great volumes of lipoaspirate are removed from the entire extremity using multiple small incisions, $4-5 \mathrm{~mm}$ cannulae and blood loss can be managed through the use of tumescent solution ( $1 \mathrm{~mL}$ of 1:1,000 epinephrine mixed with $1 \mathrm{~L}$ of normal saline).Spontaneous skin contracture is expected to resolve the skin excess after the debulking procedure ${ }^{4,104}$. A „dry" technique under tourniquet control can be accepted due to the difficulty of injecting tumescent into a severe fibrotic subcutaneous tissue ${ }^{105}$.

Long-term postoperative compression therapy is indicated to preclude fluid reaccumulation. The current contraindication are: patients who were not maximally treated conservatory, coagulopathies, anticoagulant treatment, metastatic disease, open wounds, non-compliant patient ${ }^{105}$.

SAL is considered a safe technique which enhances quality of life and decreases erysipelas frequency in postmastectomy patients ${ }^{106}$.

Although SAL does not appear to prejudice the lymphatic system transport capacity, in advanced stages of lymphedema the lymph vessels are commonly enlarged and tortuous, making them more vulnerable to injury. In this respect, to further facilitate lymphatic sparing, Campisi et al described the technique of $\mathrm{Fi}^{-}$ bro-Lipo-Lymph-Aspiration (FLLA) with a Lymph Vessel Sparing Procedure (LVSP) in which liposuction is performed in association with 2 mapping methods (a patent blue violet dye test, together with indocyanine green (ICG) fluorescence) and a photo dynamic eye (PDE) camera is used to mark and map the superficial lymphatic channels of the limb. They concluded that the limb volume improvement is linked to the elimination of tissue impediments to lymphatic flow ${ }^{107}$.

\section{Excizional procedures}

Surgical reduction is a radical approach used in advanced and debilitating stages of lymphedema that can offer satisfactory results for carefully selected patients. The Charles procedure is perhaps one of the earliest, broadly recognized reductive techniques. It implies the circumferential excision of subcutaneous tissue to the level of deep fascia or underlying epimysium followed by full thickness skin graft coverage. These skin grafts may be harvested from a different donor area or may be represented by the resected skin ${ }^{4,76,108}$.

The procedure can reduce limb volume but completely disrupts the superficial lymphatic drainage and can further worsen distal edema resulting in a bottleneck deformity. Furthermore, the skin grafted area can imply considerable morbidity related to impaired wound healing, hyperkeratosis or ulcerations ${ }^{109}$.

Several variations of the Charles procedure have been described to minimize the excessive skin grafting and to foster the lymph drainage by altering the underlying fascia:

- Kondoleon procedure adds the excision of deep facia strips in an attempt to create a communication window between superficial and deep lymphatic systems ${ }^{108}$.

- Sistrunck - a modification of the Kondoleon procedure-probably the first procedure to describe breast cancer related lymphedema; involved wedge excision of skin and lymphedematous tissue with the removal of large amounts of fascia ${ }^{108}$.

- Homans-Miller-a modification of the Kondoleon procedure-implies the removal of the excess tissue and coverage of the resected area with thin skin flaps.Often multiple operations are needed to obtain acceptable results ${ }^{93,108}$.

- Thompson procedure combines the concepts of Charles and Homans Miller in which a deepithelialized flap is rolled and buried deep to the deep fascia in order to facilitate the lymph drainage between the superficial and deep systems ${ }^{108}$.

- Van der Walt modernized the Charles procedure and used negative pressure wound therapy and 
delayed skin grafting in order to improve wound healing and graft take ${ }^{110}$.

The surgical management of lymphedema represents a challenging therapeutic area, with the need of establishing standardized indications. Figure 5 displays a comprehensive algorithm for surgical management in patients with breast cancer-related lymphedema, improving decision making in such complex cases ${ }^{1,4,92}$.

The surgeon must pose adequate experience with all the techniques exposed above, in many cases the indication being the combination between physiologic procedures and reductive proceduresin order to achieve the goal of limb volume reduction and improving patient symptomatology. This situation is particularly encountered in patients with late-stagelymphedema ${ }^{111}$.

\section{CONCLUSION}

Lymphedema is a challenging condition and a recognized factor that elicits daily stress, reduces functional competence and quality of life in affected patients. Breast cancer related lymphedema is the most common type of secondary lympedema in developed countries, a debilitating condition occurring in approximately one third of patients who underwent multimodal treatment. Health care professionals should focus on pro- moting risk reducing behaviors and timely referral to lymphedema specialists in order to minimize the disease progression. Upper limb lymphedema offers many therapeutic strategies including conservative and surgical methods that could be tailored to suit each patient individually.

Conservative treatment remains the first line of therapy in patients with installed lymphedema or in those with high risk to develop this condition. Long term adherence to those programs is mandatory for the patient. Due to the recent advances in the field of microsurgery, innovative surgical techniques have been developed to minimize or prophylactically correct lymphatic dysfunction, such as LVA or VLNT, which are promising strategies to reduce lymphedema burden. Also, in the surgical armamentarium, reductive procedures are still useful for patients with late stage lymphedema and incompetence of the lymphatic system or as complementary therapy to physiologic procedures.

Compliance with ethics requirements: The authors declare no conflict of interest regarding this article. The authors declare that all the procedures and experiments of this study respect the ethical standards in the Helsinki Declaration of 1975, as revised in 2008(5), as well as the national law. Informed consent was obtained from all the patients included in the study.

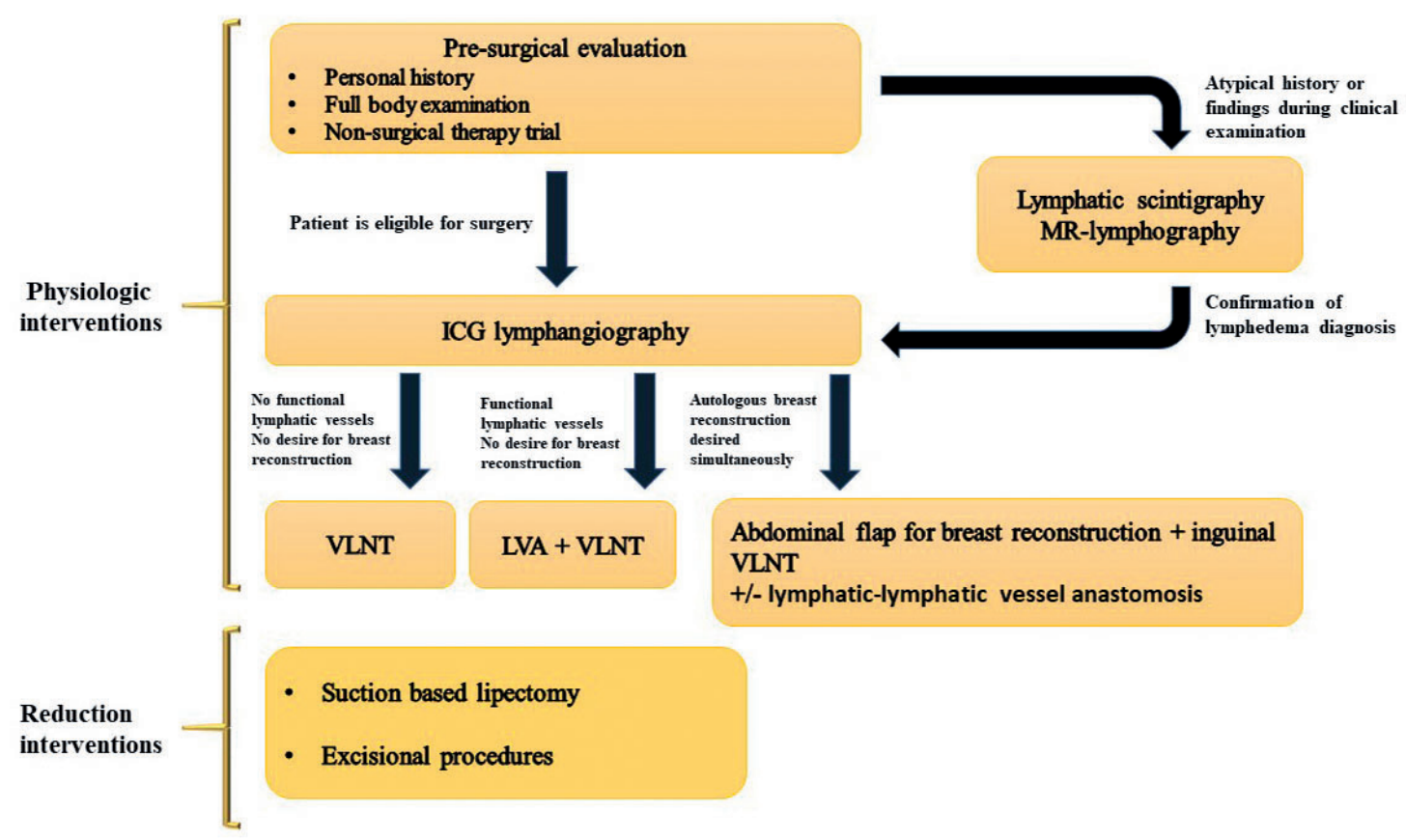

Figure 5. Algorithm for surgical management in patients with breast cancer-related lymphedema ${ }^{1,4,92}$ 


\section{References:}

1. Rustad KC, Chang DW. Surgical Approaches to the Prevention and Management of Breast Cancer-Related Lymphedema. Curr Breast Cancer Rep. 2020;33(12),185-192.

2. Silva AK, Chang DW. Vascularized lymph node transfer and lymphovenous bypass: novel treatment strategies for symptomatic lymphedema. J Surg Oncol. 2016;113(8):932-9.

3. Schulze H, Nacke M, Gutenbrunner $\mathrm{C}$ et al. Worldwide assessment of healthcare personnel dealing with lymphoedema. Health Econ Rev.2018; 8, 10: 1-11.

4. Kung TA, Champaneria MC, Maki JH, Neligan PC. Current Concepts in the Surgical Management of Lymphedema. PlastReconstr Surg. 2017 Apr;139(4):1003e-1013e.

5. Li CY, Kataru RP, Mehrara BJ. Histopathologic Features of Lymphedema: A Molecular Review. International Journal of Molecular Sciences. 2020; 21(7):2546. https://doi.org/10.3390/ ijms21072546

6. Mcfarlane ME. Primary Upper Limb Lymphedema: Case Report of a Rare Pathology. Perm J. 2017;21:16-010. doi:10.7812/TPP/16010

7. Lawenda BD, Mondry TE, Johnstone PAS. Lymphedema: a primer on the identification and management of a chronic condition in oncologic treatment. CA Cancer J Clin. 2009;59:8-24

8. Garza R 3rd, Skoracki R, Hock K, Povoski SP. A comprehensive overview on the surgical management of secondary lymphedema of the upper and lower extremities related to prior oncologic therapies. BMC Cancer. 2017;17(1):468.

9. Ayre K, Parker C. Lymphedema after treatment of breast cancer: a comprehensive review. J Unexplored Med Data 2019;4:5 . http:// dx.doi.org/10.20517/2572-8180.2019.02

10. Sleigh BC, Manna B. Lymphedema. In: StatPearls [Internet] Treasure Island (FL): StatPearls Publishing; 2021 Jan. Available from: https://www.ncbi.nlm.nih.gov/books/NBK537239/

11. Gillespie TC, Sayegh HE, Brunelle CL, Daniell KM, Taghian AG. Breast cancer-related lymphedema: risk factors, precautionary measures, and treatments. Gland Surg. 2018;7(4):379-403

12. Tandra P, Kallam A, Krishnamurthy J. Identification and Management of Lymphedema in Patients with Breast Cancer. J Onco Pract. 2019 May; 15(5):255-262.

13. Pappalardo M, Starnoni M, Franceschini G, Baccarani A, De Santis G. Breast Cancer-Related Lymphedema: Recent Updates on Diagnosis, Severity and Available Treatments. J Pers Med. 2021;11(5):402. Published 2021 May 12. doi:10.3390/ jpm11050402

14. Sayegh HE, Asdourian MS, Swaroop MN, et al. Diagnostic Methods, Risk Factors, Prevention, and Management of Breast Cancer-Related Lymphedema: Past, Present, and Future Directions. Curr Breast Cancer Rep. 2017;9(2):111-121.

15. Wilke LG, McCall LM, Posther KE, Whitworth PW, Reintgen DS, et al. Surgical complications associated with sentinel lymph node biopsy: results from a pro-spective international cooperative group trial. Ann Surg Oncol. 2006;13:491-500.

16. Miller CL, Colwell AS, Horick N, Skolny MN, Jammallo LS, O'Toole JA, Shenouda MN, Sadek BT, Swaroop MN, Ferguson CM, Smith BL, Specht MC, Taghian AG. Immediate Implant Reconstruction Is Associated with a Reduced Risk of Lymphedema Compared to Mastectomy Alone: A Prospective Cohort Study. Ann Surg. 2016 Feb;263(2):399-405

17. Zhu W, Li D, Li X, Ren J, Chen W, et al. Association between adjuvant docetaxel-based chemotherapy and breast cancer-related lymphedema. Anticancer Drugs 2017;28:350-55

18. Jammallo LS, Miller CL, Singer M, et al. Impact of body mass index and weight fluctuation on lymphedema risk in patients treated for breast cancer. Breast Cancer Res Treat 2013:142:59-67.
19. Ridner SH, Dietrich MS, Stewart BR, et al. Body mass index and breast cancer treatment-related lymphedema. Support Care Cancer 2011;19:853-7.

20. Cemal $Y$, Pusic A, Mehrara BJ. Preventative measures for lymphedema: separating fact from fiction. J Am Coll Surg. 2011;213(4):543-551

21. Dylke ES, Schembri GP, Bailey DL, Bailey E, Ward LC, Refshauge K, Beith J, Black D, Kilbreath SL. Diagnosis of upper limb lymphedema: development of an evidence-based approach. Acta Oncol. 2016 Dec;55(12):1477-1483.

22. Sierla R, Dylke ES, Shaw T, Poon S, Kilbreath SL. Assessment of Upper Limb Lymphedema: A Qualitative Study Exploring Clinicians' Clinical Reasoning. Lymphat Res Biol. 2021 Apr;19(2):151158.

23. Greene AK, Goss JA. Diagnosis and Staging of Lymphedema Semin Plast Surg. 2018;32(1):12-16.

24. Yoo JN, Cheong YS, Min YS, Lee SW, Park HY, Jung TD. Validity of Quantitative Lymphoscintigraphy as a Lymphedema Assessment Tool for Patients With Breast Cancer. Ann Rehabil Med. 2015;39(6):931-940.

25. Neligan P. Measuring Methods. Chapter in Neligan PC, Masia $J$ and Piller NB Eds., Lymphedema: Complete Medical and Surgical Management, Thieme 2016, pages 315-325.

26. Kayıran O, De La Cruz C, Tane K, Soran A. Lymphedema: From diagnosis to treatment. Turk J Surg. 2017;33(2):51-57.

27. Raghuram AC, Yu RP, Sung C. et al. The Diagnostic Approach to Lymphedema: a Review of Current Modalities and Future Developments. Curr Breast Cancer Rep. 2019;11, 365-372.

28. He L, Qu H, Wu Q, Song Y. Lymphedema in survivors of breast cancer. Oncol Lett. 2020;19(3):2085-2096. doi:10.3892/ ol.2020.11307

29. O'Donnell TF Jr, Rasmussen JC, Sevick-Muraca EM. New diagnostic modalities in the evaluation of lymphedema. J Vasc Surg Venous LymphatDisord. 2017;5(2):261-273. doi:10.1016/j. jvsv.2016.10.083

30. Kim SY, Bae H, Ji HM. Computed Tomography as an Objective Measurement Tool for Secondary Lymphedema Treated With Extracorporeal Shock Wave Therapy. Ann Rehabil Med. 2015;39(3):488-493.

31. Mitsumori LM. Magnetic Resonance Lymphangiography.Chapter in Neligan PC, Masia $\mathrm{J}$ and Piller NB Eds., Lymphedema: Complete Medical and Surgical Management, Thieme 2016, pages 379-392.

32. Guerrini S, Gentili F, Mazzei FG, Gennaro P, Volterrani L, Mazzei MA. Magnetic resonance lymphangiography: with or without contrast? Diagn IntervRadiol. 2020;26(6):587-595. doi:10.5152/ dir.2020.19482

33. Lee BB, Laredo J. Radionuclide Lymphoscintigraphy, chapter in Neligan PC, Masia J and Piller NB Eds., Lymphedema: Complete Medical and Surgical Management, Thieme 2016, pages 349-364

34. Narushima $M$, Yamamoto $T$, Ogata F, Yoshimatsu H, Mihara $M$, Koshima I. Indocyanine Green Lymphography Findings in Limb Lymphedema. J ReconstrMicrosurg. 2016 Jan;32(1):72-9. doi: 10.1055/s-0035-1564608. Epub 2015 Sep 30. PMID: 26422172.

35. Jørgensen MG, Toyserkani NM, Hansen FCG, Thomsen JB, Sørensen JA. Prospective Validation of Indocyanine Green Lymphangiography Staging of Breast Cancer-Related Lymphedema. Cancers (Basel). 2021;13(7):1540. Published 2021 Mar 26. doi:10.3390/cancers 13071540

36. Narushima M, Yamamoto T, Koshima I. Indocyanine Green Lymphography. Chapter in Neligan PC, Masia J and Piller NB Eds., Lymphedema: Complete Medical and Surgical Management, Thieme 2016, pages 365-377. 
37. Maus EA, Tan IC, Rasmussen JC, et al. Near-infrared fluorescence imaging of lymphatics in head and neck lymphedema. Head Neck. 2012;34(3):448-453. doi:10.1002/hed.21538.

38. Rasmussen JC, Tan IC, Marshall MV, Adams KE, Kwon S, Fife CE, Maus EA, Smith LA, Covington KR, Sevick-Muraca EM. Human Lymphatic Architecture and Dynamic Transport Imaged Using Near-infrared Fluorescence. Transl Oncol. 2010 Dec 1;3(6):362-72. doi: 10.1593/tlo.10190. PMID: 21151475; PMCID: PMC3000461.

39. Demirtas $Y$, Yigit B. Basic Approaches to the Diagnosis of Lymphedema: Clinicians' Perspective. Chapter in Neligan PC, Masia J and Piller NB Eds., Lymphedema: Complete Medical and Surgical Management, Thieme 2016, pages 291-297.

40. Dalal A, Eskin-Schwartz M, Mimouni D, et al. Interventions for the prevention of recurrent erysipelas and cellulitis. Cochrane Database Syst Rev. 2017;6(6):CD009758. Published 2017 Jun 20. doi:10.1002/14651858.CD009758.pub2

41. Meneses KD, McNees MP. Upper extremity lymphedema after treatment for breast cancer: a review of the literature. Ostomy Wound Manage. 2007 May;53(5):16-29. PMID: 17551172.

42. Michelini S, Cardone M, Fiorentino A. Clinical Staging of Lymphedema. chapter in Neligan PC, Masia J and Piller NB Eds., Lymphedema: Complete Medical and Surgical Management, Thieme 2016, pages 309-314.

43. Executive Committee of the International Society of Lymphology. The diagnosis and treatment of peripheral lymphedema: 2020 Consensus Document of the International Society of Lymphology. Lymphology. 2020;53(1):3-19. PMID: 32521126.

44. Douglass J, Kelly-Hope L. Comparison of Staging Systems to Assess Lymphedema Caused by Cancer Therapies, Lymphatic Filariasis, and Podoconiosis. Lymphat Res Biol. 2019;17(5):550-556. doi:10.1089//rb.2018.0063

45. Campisi C, Boccardo F. Microsurgical techniques for lymphedema treatment: derivative lymphatic-venous microsurgery. World J Surg. 2004;28(6):609-13.

46. Chang DW, Suami H, Skoracki R. A prospective analysis of 100 consecutive lymphovenous bypass cases for treatment of extremity lymphedema. PlastReconstr Surg. 2013 Nov; 132(5):13051314. doi: 10.1097/PRS.0b013e3182a4d626. PMID: 24165613

47. Chang DW, Masia J, Garza R 3rd, Skoracki R, Neligan PC. Lymphedema: surgical and medical therapy. PlastReconst Surg 2016;138:2095-185

48. Jørgensen MG, Hermann AP, Madsen AR. et al. Indocyanine green lymphangiography is superior to clinical staging in breast cancer-related lymphedema. Sci Rep 2021. 11, 21103. https://doi. org/10.1038/s41598-021-00396-2

49. Maclellan RA, Couto RA, Sullivan JE, Grant FD, Slavin SA, Greene AK. Management of primary and secondary lymphedema: analysis of 225 referrals to a center. Ann Plast Surg. 2015;75(2):197200

50. National Comprehensive Cancer Network, available on https:// www.nccn.org/

51. Bergmann A, Baiocchi JMT, de Andrade MFC. Conservative treatment of lymphedema: the state of the art. J Vasc Bras. 2021 Oct 11;20:e20200091. doi: 10.1590/1677-5449.200091. PMID 34777487; PMCID: PMC8565523.

52. Borman P. Lymphedema diagnosis, treatment, and follow-up from the view point of physical medicine and rehabilitation specialists. Turk J Phys Med Rehabil. 2018;64(3):179-197. Published 2018 Sep 3. doi:10.5606/tftrd.2018.3539

53. Piller NB. Conservative Treatments for Lymphedema, chapter in Neligan PC, Masia J and Piller NB Eds., Lymphedema: Complete Medical and Surgical Management, Thieme 2016, pages 395-406

54. Keskin D, Dalyan M, Ünsal-Delialioğlu S, Düzlü-Öztürk Ü. The results of the intensive phase of complete decongestive therapy and the determination of predictive factors for response to treat- ment in patients with breast cancer related-lymphedema. Cancer Rep (Hoboken). 2020;3(2):e1225. doi:10.1002/cnr2.1225

55. Michopoulos E, Papathanasiou G, Vasilopoulos G, Polikandrioti M, Dimakakos E. Effectiveness and Safety of Complete Decongestive Therapy of Phase I: A Lymphedema Treatment Study in the Greek Population. Cureus. 2020;12(7):e9264. Published 2020 Jul 19. doi:10.7759/cureus.9264

56. Rabe E, Partsch H, Morrison N, et al. Risks and contraindications of medical compression treatment - A critical reappraisal. An international consensus statement. Phlebology. 2020;35(7):447460. doi: $10.1177 / 0268355520909066$

57. Ezzo J, Manheimer E, McNeely ML, et al. Manual lymphatic drainage for lymphedema following breast cancer treatment. Cochrane Database Syst Rev. 2015;(5):CD003475. Published 2015 May 21. doi:10.1002/14651858.CD003475.pub2

58. Batavia M, Manual Lymphatic Drainage. Chapter in Batavia $\mathrm{M}(\mathrm{Ed})$ Contraindications in Physical Rehabilitation,W.B. Saunders,2006,Pages 245-254.

59. Zuther Je. Lymphedema Management: The Comprehensive Guide for Practitioners 2nd edition,Thieme Stuttgart 2009.

60. Lim CS, Davies AH. Graduated compression stockings. CMAJ. 2014;186(10):E391-E398. doi:10.1503/cmaj.131281

61. Scheer R. Compression garments for managing lymphoedema. Journal of Lymphoedema, 2017, Vol 12, No 1.pp 39-45.

62. National Lymphedema Network. Exercise: Position Statement of the National Lymphedema Network. NLN Medical Advisory Committee, updated May 2011. Available at www.lymphnet.org.

63. Douglass J, Mableson HE, Martindale S, Kelly-Hope LA. An enhanced self-care protocol for people affected by moderate to severe lymphedema. Methods Protoc. 2019;2(3):77. http://dx.doi. org/10.3390/mps2030077.

64. Fife CE, Farrow W, Hebert AA, et al. Skin and wound care in lymphedema patients: a taxonomy, primer, and literature review. Adv Skin Wound Care. 2017;30(7):305-18.

65. Moortgat P, Anthonissen M, Meirte J, Van Daele U, Maertens K. The physical and physiological effects of vacuum massage on the different skin layers: a current status of the literature. Burns Trauma. 2016;4:34. Published 2016 Sep 19. doi:10.1186/s41038016-0053-9

66. Kubo M, Li TS, Kamota T, Ohshima M, Shirasawa B, Hamano K. Extracorporeal shock wave therapy ameliorates secondary lymphedema by promoting lymphangiogenesis. J Vasc Surg. 2010;52(2):429-34

67. Forte AJ, Boczar D, Huayllani MT, McLaughlin SA, Bagaria S. Topical Approach to Delivering Targeted Therapies in Lymphedema Treatment: A Systematic Review. Cureus. 2019;11(12):e6269. Published 2019 Dec 1. doi:10.7759/cureus.6269

68. Wang K. Pharmacologic Treatment of Lymphedema, chapter in Neligan PC, Masia J and Piller NB Eds., Lymphedema: Complete Medical and Surgical Management, Thieme 2016, pages 407-421.

69. Nakamura K, Radhakrishnan K, Wong YM, Rockson SG. Anti-inflammatory pharmacotherapy with ketoprofen ameliorates experimental lymphatic vascular insufficiency in mice. PLoS One. 2009;4(12):e8380. Published 2009 Dec 21. doi:10.1371/journal. pone.0008380

70. Rockson SG, Tian W, Jiang $X$, et al. Pilot studies demonstrate the potential benefits of antiinflammatory therapy in human lymphedema. JCI Insight. 2018;3(20):e123775. Published 2018 Oct 18. doi:10.1172/jci.insight.123775

71. Gardenier JC, Kataru RP, Hespe GE, et al. Topical tacrolimus for the treatment of secondary lymphedema. Nat Commun. 2017:8:14345. Published 2017 Feb 10. doi:10.1038/ ncomms 14345

72. Hu LR, Pan J. Adipose-derived stem cell therapy shows promising results for secondary lymphedema. World J Stem Cells 2020; 12(7): 612-620. 
73. Kareh AM, Xu KY. Surgical Management of Lymphedema. Mo Med. 2020;117(2):143-148.

74. Jabbour S, Chang El. Recent advancements in supermicrosurgical treatment of lymphedema. PlastAesthet Res 2021;8:43. http:// dx.doi.org/10.20517/2347-9264.2021.59

75. Granzow JW. Lymphedema surgery: the current state of the art. Clin Exp Metastasis. 2018 Aug;35(5-6):553-558. doi: 10.1007/ s10585-018-9897-7. Epub 2018 Jul 6. PMID: 29980891

76. Park KE, Allam O, Chandler $L$, et al. Surgical management of lymphedema: a review of current literature. Gland Surg. 2020:9(2):503-511. doi:10.21037/gs.2020.03.14

77. Forte AJ, Sisti A, Huayllani MT, et al. Lymphaticovenular anastomosis for breast cancer-related upper extremity lymphedema: a literature review. Gland Surg. 2020;9(2):539-544. doi:10.21037/ gs.2020.03.41

78. Chang El, Skoracki RJ, Chang DW. Lymphovenous Anastomosis Bypass Surgery. Semin Plast Surg. 2018;32(1):22-27. doi:10.1055/s-0038-1636510

79. Campisi C, Campisi CC, Boccardo F. Lymphatic-Venous Derivative and Reconstructive Microsurgery. Chapter in : Lee BB, Rockson S, Bergan J. (eds) Lymphedema. Springer, Cham. 2018.

80. Seki Y, Kajikawa A. Fundamental and essential techniques for supermicrosurgical lymphaticovenular anastomosis: the art of Isao Koshima'ssupermicrosurgery. PlastAesthet Res 2021:8:44 http://dx.doi.org/10.20517/2347-9264.2021.74

81. Gennaro P, Gabriele G, Salini C, Chisci G, Cascino F, Xu JF, Ungari C. Our supramicrosurgical experience of lymphaticovenular anastomosis in lymphoedema patients to prevent cellulitis. Eur Rev Med Pharmacol Sci. 2017 Feb;21(4):674-679.

82. Masia J, Pons G, Nardulli ML. Combined Surgical Treatment in Breast Cancer-Related Lymphedema. J ReconstrMicrosurg. 2016 Jan;32(1):16-27. doi: 10.1055/s-0035-1544182. Epub 2015 Apr 13. PMID: 25868153.

83. Koshima I, Inagawa K, Urushibara K, Moriguchi T. Supermicrosurgical lymphaticovenular anastomosis for the treatment of lymphedema in the upper extremities. J ReconstrMicrosurg 2000;16:437-42

84. Yamamoto T, Yamamoto N, Kageyama T, et al. Technical pearls in lymphatic supermicrosurgery. Glob Health Med 2020;2:29-32.

85. Nagase T, Gonda K, Inoue K, Higashino T, Fukuda N, Gorai K, Mihara M, Nakanishi M, Koshima I. Treatment of Iymphedema with lymphaticovenular anastomoses. Int J Clin Oncol. 2005 Oct;10(5):304-10. doi: 10.1007/s10147-005-0518-5. PMID: 16247656

86. Akita S, Unno N, Maegawa J, et al. HAMAMATSU-ICG study: Protocol for a phase III, multicentre, single-arm study to assess the usefulness of indocyanine green fluorescent lymphography in assessing secondary lymphoedema. Contemp Clin Trials Commun. 2020;19:100595. Published 2020 Jun 16. doi:10.1016/j. conctc. 2020.100595

87. Campisi CC, Molinari L, Campisi CS, Villa G, Fulcheri E, Campisi C. Surgical research, staging-guided technical procedures and long-term clinical outcomes for the treatment of periphera lymphedema: the Genoa Protocol. Journal of Surgery and Surgical Research, 2020, 6.1: 041-050.

88. Ozmen T, Lazaro M, Zhou Y, Vinyard A, Avisar E. Evaluation of Simplified Lymphatic Microsurgical Preventing Healing Approach (S-LYMPHA) for the Prevention of Breast Cancer-Related Clinical Lymphedema After Axillary Lymph Node Dissection. Ann Surg. 2019 Dec;270(6):1156-1160. doi: 10.1097/ SLA.0000000000002827. PMID: 29794843.

89. Agarwal S, Garza RM, Chang DW. Lymphatic Microsurgical Preventive Healing Approach (LYMPHA) for the prevention of secondary lymphedema. Breast J. 2020 Apr;26(4):721-724. doi: 10.1111/tbj.13667. Epub 2019 Oct 20. PMID: 31631442

90. Schwarz GS, Grobmyer SR, Djohan RS, Cakmakoglu C, Bernard SL, Radford D, Al-Hilli Z, Knackstedt R, Djohan M, Valente SA. Axil- lary reverse mapping and lymphaticovenous bypass: Lymphedema prevention through enhanced lymphatic visualization and restoration of flow. J Surg Oncol. 2019 Aug;120(2):160-167. doi: 10.1002/jso.25513. Epub 2019 May 29. PMID: 31144329.

91. Baumeister RGH. Lymphatic vessel transplantation. Chapter in Greene A, Slavin S, Brorson H. (eds). Lymphedema. Springer, Cham. 2015. 247-254

92. Masià J, Pons G, Rodríguez-Bauzà E. Barcelona Lymphedema Algorithm for Surgical Treatment in Breast Cancer-Related Lymphedema. J ReconstrMicrosurg. 2016 Jun;32(5):329-35. doi: 10.1055/s-0036-1578814. Epub 2016 Mar 14. PMID: 26975564.

93. Schaverien MV, Badash I, Patel KM, Selber JC, Cheng MH. Vascularized Lymph Node Transfer for Lymphedema. Semin Plast Surg. 2018 Feb;32(1):28-35. doi: 10.1055/s-0038-1632401. Epub 2018 Apr 9. PMID: 29636651; PMCID: PMC5891655.

94. Chocron Y, Azzi AJ, Bouhadana G, Kokosis G, Vorstenbosch J. Axilla versus Wrist as the Recipient Site in Vascularized Lymph Node Transfer for Breast Cancer-Related Lymphedema: A Systematic Review and Meta-Analysis. J ReconstrMicrosurg. 2021. doi: 10.1055/s-0041-1740132. Epub ahead of print. PMID: 34875698.

95. Lafuente H, Jaunarena I, Ansuategui E, Lekuona A, Izeta A. Cell therapy as a treatment of secondary lymphedema: a systematic review and meta-analysis. Stem Cell Res Ther. 2021;12(1):578. Published 2021 Nov 20. doi:10.1186/s13287-021-02632-y

96. Schaverien MV, Chang El. Combined deep inferior epigastric artery perforator flap with vascularized groin lymph node transplant for treatment of breast cancer-related lymphedema. Gland Surg. 2021;10(1):460-468. doi:10.21037/gs.2020.02.14

97. Chang El, Schaverien MV, Hanson SE, Chu CK, Hanasono MM. Evolution in Surgical Management of Breast Cancer-related Lymphedema: The MD Anderson Cancer Center Experience. PlastReconstr Surg Glob Open. 2020;8(3):e2674. Published 2020 Mar 27. doi:10.1097/GOX.0000000000002674

98. Ciudad P, Sabbagh MD, Agko M, Huang TCT, Manrique OJ, L CR, Reynaga C, Delgado R, Maruccia M, Chen HC. Surgical Management of Lower Extremity Lymphedema: A Comprehensive Review. Indian J Plast Surg. 2019 Jan;52(1):81-92. doi: 10.1055/s0039-1688537. Epub 2019 May 14. PMID: 31456616; PMCID: PMC6664851.

99. Lee BB.State of art in lymphedema management: part 2.Phlebolymphology.2018; 25.3: 189-200.

100. Lee BB, Kim YW, Kim DI, Hwang JH, Laredo J, Neville R. Supplemental surgical treatment to end stage (stage IV-V) of chronic lymphedema. Int Angiol. 2008 Oct;27(5):389-95. PMID: 18974701

101. Brorson H, Svensson H. Liposuction combined with controlled compression therapy reduces arm lymphedema more effectively than controlled compression therapy alone. PlastReconstr Surg. 1998;102(4):1058-1067

102. Zampell JC, Aschen S, Weitman ES, Yan A, Elhadad S, De Brot Andrade M, Mehrara BJ. Regulation of adipogenesis by lymphatic fluid stasis: part I. Adipogenesis, fibrosis, and inflammation. PlastReconstr Surg. 2012 Apr;129(4):825-834. doi: 10.1097/PRS.0b013e3182450b2d. PMID: 22456354; PMCID: PMC3433726.

103. Aschen S, Zampell JC, Elhadad S, Weitman E, De Brot Andrade M, Mehrara BJ. Regulation of adipogenesis by lymphatic fluid stasis: part II. Expression of adipose differentiation genes. PlastReconstr Surg. 2012 Apr;129(4):838-847. doi: 10.1097/PRS.0b013e3182450b47. PMID: 22456356; PMCID: PMC3445411.

104. Chen WF, Zeng WF, Hawkes PJ, Man J, Bowen M. Lymphedema Liposuction with Immediate Limb Contouring. PlastReconstr Surg Glob Open. 2019 Nov 12;7(11):e2513. doi: 10.1097/GOX.0000000000002513. PMID: 31942304; PMCID: PMC6908351.

105. Schaverien MV, Munnoch DA, Brorson H. Liposuction treatment of lymphedema. Semin Plast Surg. 2018;32:42-47 
106. Lee D, Piller N, Hoffner M, Manjer J, Brorson H. Liposuction of postmastectomy arm lymphedema decreases the incidence of erysipelas. Lymphology. 2016;49(2):85-92.

107. Campisi CC, Ryan M, Boccardo F, Campisi C. Fibro-lipo-lymph-aspiration with a lymph vessel sparing procedure to treat advanced lymphedema after multiple lymphatic-venous anastomoses: the complete treatment protocol. Ann Plast Surg. 2017;78:184e190

108. Champaneria MC, Neligan PC. Excisional Approaches for the Treatment of Lymphedema.available on https://plasticsurgerykey.com/chapter-31-excisional-approaches-for-the-treatment-of-lymphedema/

109. Mavili ME, Naldoken S, Safak T. Modified Charles operation for primary fibrosclerotic lymphedema. Lymphology. 1994;27:14-20.

110. van der Walt JC, Perks TJ, Zeeman BJ, et al. Modified Charles procedure using negative pressure dressings for primary lymphedema: a functional assessment. Ann Plast Surg 2009;62:669-75

111. Ciudad P, Manrique OJ, Adabi K, Huang TCT, Agko M, Trignano $E$, et al. Combined double vascularized lymph node transfers and modified radical reduction with preservation of perforators for advanced stages of lymphedema. J Surg Oncol. 2019;119(4):43948. 